farther to the north. Merhart's well-known work on the Siberian Palæolithic cultures deals, of course, with discoveries of an earlier period. "The Neolithic Age in Eastern Siberia", therefore, fills a yawning gap in our knowledge of the region. The reader will do well to turn to Table 2 on p. 33 and to read the accounts of the finds in the light of the chronological sequence there set out. Not everyone agrees as to the origins of these various cultures. Fundamentally, however, it would seem that a case has been made out for connexions with the west, for example, with such an area as south Russia. Whether the Magdalenians, drifting north and east following the reindeer and retreating before the ameliorating climate of western Europe, ever reached Siberia is very uncertain, though the possibility should not be ruled out. Anyway, there seems to occur a sort of late PalæolithicMesolithic complex and this is followed by a transitional (Khina) culture which in turn heralds the early Neolithic industries (Isakovo) with some pottery and polished stone tools. Naturally in such an isolated region local developments occur. There follow the various Neolithic cultures, and after them those of the true Bronze and Iron Ages. Many of the ideas put forward ar e necessarily tentative, but the volume does bring up to date what is known of the earlier Stone Ages of these remote regions.

\section{New Vaccine for Fowl Typhoid}

A NEW immunizing agent for use against fowl typhoid is now available to the poultry industry. Following initial work by Dr. H. Williams Smith, an Animal Health Trust bacteriologist, on the organism causing this costly and highly infectious disease, the Trust has evolved a 'live' vaccine the efficiency of which has been thoroughly tested and proved in a series of field trials carried out in collaboration with the Veterinary Investigation Service of the Ministry of Agriculture. Prepared from a strain of the organism which is less virulent than most, the new vaccine, known as ' $9 R S$ ', is free from the drawbacks associated with the use of earlier 'live' products --the risk of setting up active disease in the field, and the liability to cause reactions inimical to the success of normal blood-testing for both B.W.D. and fowl typhoid itself. It is therefore completely safe, and supplies for home administration are now offered for sale to all poultry-keepers. It is emphasized that the purpose of the vaccine is to prevent fowl typhoid. It is not a cure. As an illustration of its preventive power, it was shown in one trial that, of a group of birds vaccinated with $9 R S$ and later artificially infected with fowl typhoid, only 6 per cent died, whereas a similar group of unvaccinated birds suffered a 70 per cent death-rate. Further information can be obtained from the Animal Health Trust, Biological Products Department, Kennett, Nr. Newmarket, Suffolk.

\section{Sputniks 1 and 2}

Mucr of the preliminary orbital data on the first two Sputniks obtained by staff of the Smithsonian Astrophysical Observatory up to March 1958 is collected in Smithsonian Contributions to Astrophysics (2, No. 10: Orbital Data and Preliminary Analyses of Satellites 1957 Alpha and 1957 Beta. Compiled by F. L. Whipple, L. G. Boyd, J. A. Hynek and G. F. Schilling. Pp. vii $+189-347$. Washington, I).C. : Government Printing Office, 1958. 1 dollar). The aim of the compilation is to publicize the orbital information as quickly as possible, and the various items are printed unrevised. The volume is thus a historical record rather than a critical survey, and many of the early orbital determinations, which were inevitably erroneous, are given equal emphasis with later and more accurate computations. This should be borne in mind when reading the volume, the contents of which are rather varied. There are a good deal of orbital information and a useful glossary of astronomical terms. There are lists of the optical observations of the satellites made by 'Moonwatch' teams, and of the daily predictions transmitted by Moscow radio. There are also two papers giving values of upper-atmosphere density deduced from the Sputnik observations, and the suggested 'interim standard atmosphere No. 2' has, in fact, successfully fitted the results from later satellites.

\section{Medical Electronics}

A RECENT meeting of an interim committee composed of members of the Institution of Electrical Engineers and of the medical profession having a common interest in medical electronics discussed the scope and future activities of the Medical Electronics Discussion Group, which has been set up by the Institution of Electrical Engineers. An organizing committee, responsible for arranging the programme of the Group, was appointed under the chairmanship of Mr. S. J. Emerson. It was decided that the activities of the Group should be centred around advanced electronic techniques applied or related to medical and biological problems, and there will be a programme of informal discussion meetings which will provide a forum for the exchange of information between the two professions on subjects coming within this field.

The first meeting of the Group is to be held at the Institution of Electrical Engineers at $6 \mathrm{p.m}$. on November 7, when Dr. A. C. Dornhorst (St. Thomas's Hospital Medical School) will speak on "Measurements' of Blood Flow in the Human Subject", and Dr. D. A. MeDonald (St. Bartholomew's Hospital Medical College) will speak on "Measurement of Pulsatile Blood Flow". A second meeting will be held on November 28 to discuss the problems which are encountered in the field of neurophysiology, when the speakers will be Dr. Warren S. McCulloch (Massachusetts Institute of Technology) and Dr. W. K. Taylor (University College, London). A third meeting in January 1959 will deal with "The Physiologists' Requirements for d.c. Amplifiers". It is proposed to provide an opportunity at each discussion meeting for members to give notice of any problems they have encountered (not necessarily related to the topic discussed at the meeting), in the hope that others present may be able to offer suggestions for their resolution. Further information can be obtained from the Secretary, Institution of Electrical Engineers, Savoy Place, London, W.C.2.

\section{Department of Scientific and Industrial Research, Research Fellowships}

T'HE following fourteen research fellowships have been awarded by the Department of Scientific and Industrial Research for the academic year 1958-59 to young research workers of exceptional promise who, usually, have already received postgraduate training up to the level of a doctorate: C. J. Batty (nuclear physics, Birmingham), L. B. Tarlo (palæontology, British Museum), J. Biggs (chemistry, 